\title{
DEVELOPMENT A KEY COMPETITIVENESS INDICATORS FOR DISASTER MANAGEMENT
}

\begin{abstract}
Industrial organizations are often encouraged to develop proactive and rigorous disaster management practices. Disaster improvements are often very expensive. Thus, industries try to use more and more innovative and effective tools to reduce the disaster risk. The purpose of this study is to identify and prioritize the key competitiveness indicators to develop a model for the analysis of disaster costs using AHP technique.
\end{abstract}

Keywords: AHP, Disaster, Cost Reduction, Optimization, Industrial plant.

\section{Introduction}

The disaster management is one of the most important element in the company, but the disaster improvements are usually expensive. In this paper an innovative assessment framework is developed using an Analytic Hierarchy Model (AHP) (Saaty, 1980; Farrow, 2002).

\section{Literature Review}

The Analytic Hierarchy Process breaks down a decision-making problem into several levels in such a way that they form a hierarchy with unidirectional hierarchical relationships between levels (De Felice and Petrillo, 2014). The AHP approach is extremely useful for developing a disaster model to mitigate costs (Aminbakhsh et al., 2013; De Felice et al., 2015).

\section{Hypotheses/Objectives}

The objective of the study is the development of an AHP model for the analysis of disaster costs. The assumptions underlying the model are the complete economic quantifiable of disaster improvements. The consistency of judgments is provided by the AHP model.

\section{Research Design/Methodology}

The AHP model (Figure 1) is built with the help of disaster management of the company. 
GOAL

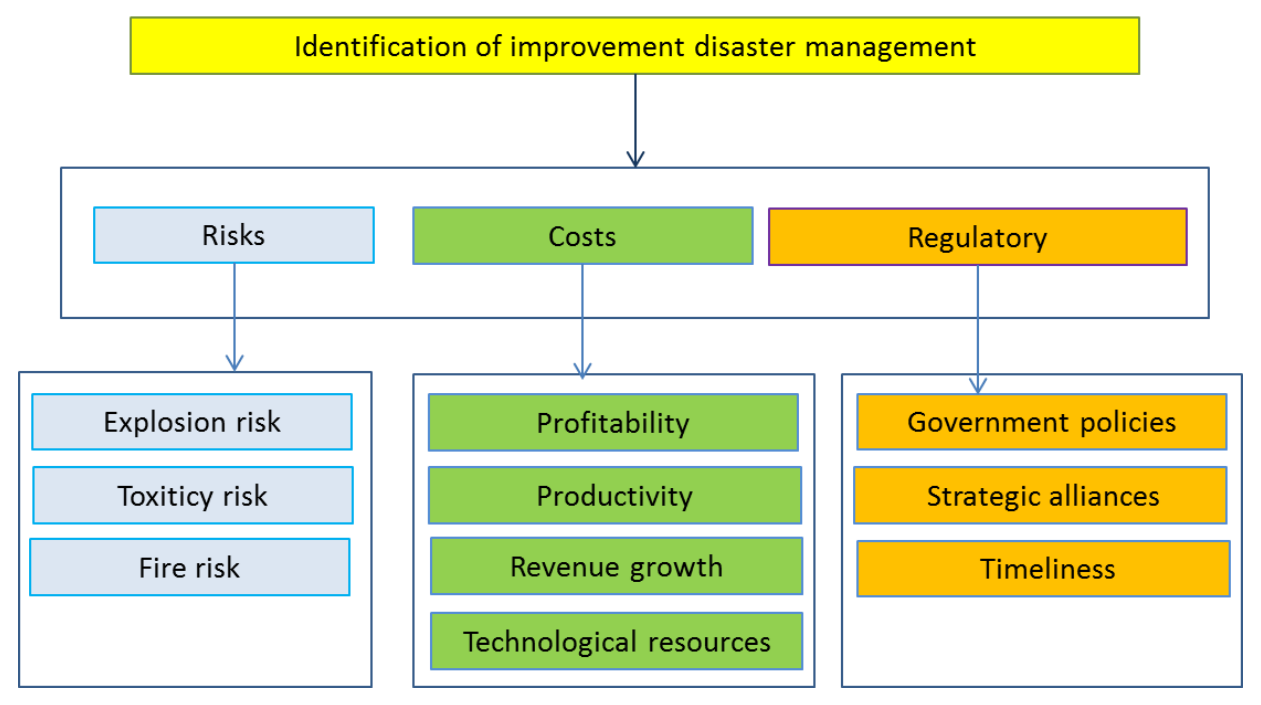

Figure 1: AHP Disaster Model

\section{Data/Model Analysis}

The judgments of expert team were aggregated using geometric mean. Results are shown in Table 1.

Table 1: Weights of criteria and subcriteria.

\begin{tabular}{|l|r|l|l|l|r|}
\hline Risks & 0,35 & Costs & 0,45 & Regulatory & 0,2 \\
\hline \hline Explosion risk & 0,37 & Profitability & 0,31 & Government policies & 0,35 \\
\hline Toxicity reduction & 0,34 & Productivity & 0,28 & Strategic alliances & 0,2 \\
\hline Fire risk & 0,29 & Revenue growth & 0,22 & Timeliness & 0,45 \\
\hline & & Technological resources & 0,19 & & \\
\hline
\end{tabular}

The key identified indicators include:

- Risk Assessment: RA = Number of disaster measures/Number of disaster measures required by regulatory;

- Frequency Index: FI = Number of total of injuries/number of employees;

- Costs: $\mathrm{C}=$ Accident annual cost/ annual revenue.

\section{Limitations}

The proposed model provides a qualitative and quantitative assessment of disaster management but it is limited to a particular set of risks characterizing a petrochemical industry. Future research will be focused on an extension of the model including a deeper analysis of risks. Furthermore, will be investigated the use of Analytic Network Process in order to analyze interaction of various factors. 
ISAHP Article: A Style Guide for Paper Proposals To Be Submitted to the International Symposium on the Analytic Hierarchy Process 2016, London, U.K.

\section{Conclusions}

The potential value of this model is that it provides a decision support system framework for assessing and benchmarking the best "compromise" to select an innovative disaster management system considering both objective and subjective criteria. It is not only a promising methodology to resolve disaster problem of industry system, but also helps managers in decision makers of disaster assessment and decision-making.

\section{Key References}

Aminbakhsh, S., Gunduz, M., \& Sonmez, R. (2013). Disaster risk assessment using analytic hierarchy process (AHP) during planning and budgeting of construction projects. Journal of Disaster Research, 46, 99-105.

Farrow S. (2002). Investing in disaster: an analytical precautionary principle. Journal of Disaster Research, 33:165-74.

De Felice, F. \& Petrillo, A. (2014). Proposal of a structured methodology for the measure of intangible criteria and for decision making. International Journal of Simulation and Process Modelling, 9, 157-166.

De Felice, F., Petrillo A., Bruzzone, A., Longo, F., 2015. A fuzzy cognitive maps model to develop a risk analysis model through the identification of critical human factors. Proceedings of $27^{\text {th }}$ European Modeling and Simulation Symposium, EMSS 2015, Pages 250-257. ISBN: 978-889799948-5.

Saaty, T.L. (1980). The Analytic Hierarchy Process. (3rd ed.). New York: McGraw-Hill. 